\title{
Sarampión en México, 2020
}

\section{Measles in Mexico, 2020}

\author{
Laura Erika García-Carrillo, ${ }^{1}$ José de Jesús Coria-Lorenzo, ${ }^{2}$ Nancy Carmencita Alonso-Pérez, ${ }^{3}$ Rómulo Erick \\ Rosales-Uribe ${ }^{4}$
}

\begin{abstract}
Resumen
El sarampión es una enfermedad susceptible de prevención mediante vacuna; es causa de más de 100,000 muertes al año. El único reservorio del virus del sarampión es el hombre, y esta característica es lo que hace que sea erradicable. En el decenio de 1960 el sarampión fue la principal causa de morbilidad y mortalidad infantil, responsable de más de 2 millones de muertes anuales, hasta la vacunación masiva en el decenio de 1980, lo que ha disminuido la incidencia y mortalidad en los últimos 20 años. La reducción en la incidencia y la mortalidad, junto con el progreso en la erradicación de la polio, han renovado el interés en la eliminación regional y global del sarampión; sin embargo, más allá de los recursos financieros y tecnológicos se requieren objetivos regionales para llevarla a cabo. Esta revisión muestra el comportamiento del sarampión en México hasta mediados del mes de junio del 2020.

PALABRAS CLAVE: Sarampión; inmunización; niños; vacuna; incidencia; México; poliomielitis.
\end{abstract}

\section{Abstract}

Measles is still a very important disease preventable by immunization which is responsible for more than 100,000 deaths per year. The only known host is human and this is the reason to be eradicable. In the sixties, measles was one of the main causes of morbidity and mortality in children, had caused about more than 2 million of deaths until the massive introduction of the vaccine by the 80 's, which diminished the incidence and mortality in the last twenty years.

The reduction in the incidence and mortality together with the progress of polio eradication, had renewed the interest on eradication regional and global of measles, although economical sources and technological there are need regional objectives to get it. The authors wrote this paper to show how the behavior in Mexico up to middle of June 2020 is.

KEYWORDS: Measles; Immunization; Children; Vaccine; Incidence; Mexico; Poliomyelitis.

\footnotetext{
1 Infectóloga pediatra, Maestra en Ciencias Médicas UNAM, gestora de calidad, Hospital General Dr. Maximiliano Ruiz Castañeda, Naucalpan, Estado de México.

${ }^{2}$ Infectólogo pediatra, Hospital Infantil de México Federico Gómez, Ciudad de México.

${ }^{3}$ Jefa de Infectología Pediátrica, Hospital Militar de Especialidades de la Mujer y Neonatología, Ciudad de México.

${ }^{4}$ Infectólogo pediatra, jefe de la Subdirección de Atención Integral al Paciente, Hospital Infantil de México Federico Gómez, Ciudad de México.
}

Recibido: 25 de junio de 2020

Aceptado: 18 de enero de 2021

Correspondencia

Laura Erika García-Carrillo

erika_garcia_carrillo@yahoo.com.mx

Este artículo debe citarse como: GarcíaCarrillo LE, Coria-Lorenzo JJ, AlonsoPérez NC, Rosales-Uribe RE. Sarampión en México, 2020. Acta Pediatr Méx 2021; 42 (3): 128-141.

\section{ANTECEDENTES}

El sarampión es una enfermedad viral, susceptible de prevención mediante vacunación, exantemática, de alta trasmisibilidad y que se había logrado mantener en cifras bajas en México. En el grupo de edad pediátrica tiene una elevada morbilidad y mortalidad. Desde hace varios años, ante la aparición de grupos antivacunas se incrementó la cantidad de casos en el mundo y se conoce muy bien la existencia de brotes en distintos países. En México, la última epidemia de sarampión ocurrió en 1989-1990 y se reportaron 89,163 casos; el último caso 
autóctono en nuestro país se registró en 1995. Desde entonces solo se habían reportado casos importados. ${ }^{1,2}$

La infección por el virus del sarampión también se considera importante debido a que, paradójicamente, produce una supresión inmunitaria transitoria que puede durar hasta dos años y conducir a enfermedades oportunistas o incrementar el riesgo de mortalidad. ${ }^{3}$

Si bien se manifiesta de manera simultánea con la enfermedad de COVID-19 ocasionada por el virus SARS-CoV-2, el brote de sarampión en México no debe pasar inadvertido porque la Organización Mundial de la Salud (OMS) estimó que en el 2018 hubo más de 140,000 defunciones, sobre todo de niños menores de 5 años de edad, y ello podría de alguna manera repercutir en la mortalidad que habrá de registrarse en México asociada con este nuevo brote, recordando que el ser humano es el único reservorio del virus del sarampión. ${ }^{4,5}$

El objetivo de esta revisión es ofrecer a la comunidad médica un panorama de la situación epidemiológica actual del sarampión en México, con sus correspondiente antecedentes históricos, que le permita sospechar, diagnosticar y tratar adecuadamente a sus pacientes.

Existen reportes de casos de sarampión desde los siglos V y VII, cuando se asociaba con el virus de rinderpest (peste bovina), un antecesor que afectaba al ganado, pero que desde el siglo XI y XII se identificaron casos en humanos. A pesar de que el médico persa Rhazes fue el primero en intentar distinguir la viruela del sarampión, Sydenham fue el primero en hacerlo de forma exitosa y detalladamente.

El sarampión se introdujo en América en el siglo XVII, a través de los colonizadores europeos al mismo tiempo que la viruela y la sífilis, entre otras enfermedades. ${ }^{1,6}$ El primer aislamiento del virus lo hicieron John Enders y Tomas Peeble en 1954 en la sangre y secreciones de un paciente. La primera cepa se denominó Edmonston por el nombre del paciente (David Edmonston) de quien se aisló y fue subcultivada en diferentes tipos de líneas celulares para la preparación de una primera vacuna experimental. La primera vacuna contra el sarampión se logró gracias a varias atenuaciones y diversos cultivos celulares (pases) de la cepa Edmonston-Zagreb hasta transformarse en la vacuna atenuada "Edmonston B", prácticamente disponible a partir de 1960, y comercializada en Estados Unidos con inicio en 1963 y que se aplicó extensamente hasta $1975.5,7,8,9$

El virus del sarampión pertenece a la familia Paramyxoviridae y al género morbillivirus, es un virus de simetría helicoidal, ARN de polaridad negativa no segmentado, con aproximadamente 15,984 nucleótidos que codifica 8 proteínas virales y que posee, además, una ARN polimerasa unida al ARN. La nucleocápside helicoidal está rodeada por una envoltura lipídica y tiene 3 proteínas relevantes en patogenia: la proteína $M$ (no glicosilada), la glicoproteína HN (glicosilada) con actividad hemaglutinina y neuroaminidasa y la glicoproteína $F$, que participa en fenómenos de fusión (Figura 1). Se trasmite por aerosoles, con puerta de entrada en el aparato respiratorio o por contacto directo con secreciones respiratorias que originan una enfermedad sistémica. El virus permanece en al aire o en las superficies contaminadas hasta por 2 horas. El ser humano es el único reservorio de este agente etiológico. ${ }^{10,11,12}$

\section{Inmunidad}

Después que una persona se infecta con el virus del sarampión se produce, inicialmente, una respuesta inmunitaria de tipo celular y, enseguida, una mediada por anticuerpos; esta suele coincidir con la aparición del exantema. Las concentraciones de anticuerpos disminuyen en los años siguientes a la infección, pero no así 


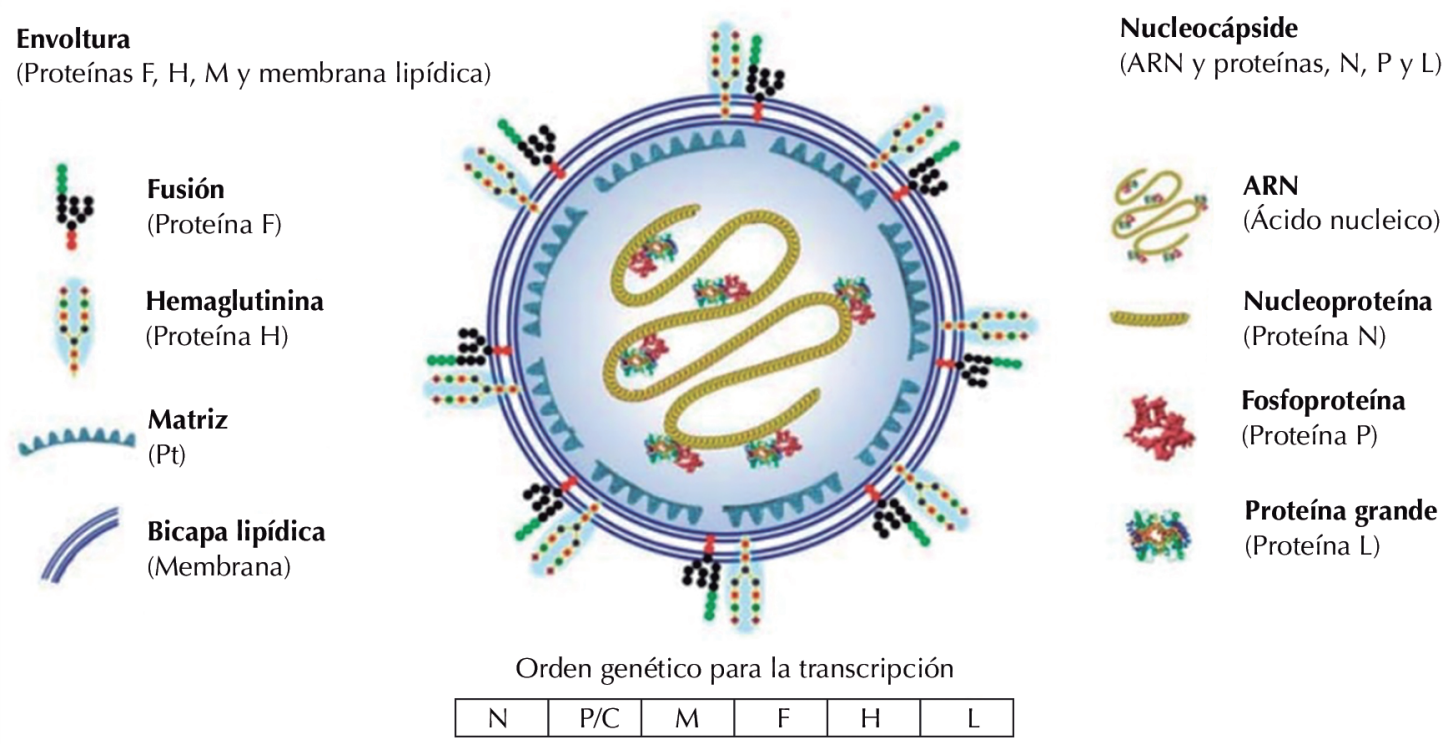

Figura 1. Virus del sarampión, proteínas F, H y M. Tomado de la referencia 22.

la inmunidad celular específica contra el virus del sarampión, que persiste de por vida. No obstante, algunas personas con concentraciones de anticuerpos muy bajas o indetectables pueden ser susceptibles al sarampión. Esta es la razón por la que la infección natural por sarampión suele inducir concentraciones de anticuerpos mayores que la vacunación contra la enfermedad. De hecho, los recién nacidos de madres que les dio sarampión suelen estar protegidos contra éste durante varios meses, aunque la protección está en función de la concentración de anticuerpos maternos adquiridos pasivamente. Esta protección disminuye entre los 6 y 9 meses de edad y aumenta, progresivamente, su vulnerabilidad al sarampión.

Los lactantes de países no endémicos, cuyas madres han sido vacunadas contra el sarampión y no han estado nunca expuestas al virus circulante, pueden recibir menos anticuerpos maternos $y$, por consiguiente, dejar de estar protegidos contra el sarampión a una edad más temprana que los lactantes cuyas madres tuvieron el sarampión. Por esto, una dosis infecciosa grande de una cepa salvaje circulante puede, ocasionalmente, superar la protección que confieren los anticuerpos maternos y producir sarampión en lactantes de 3 o 4 meses de vida. ${ }^{9,10}$

\section{Cuadro clínico}

El virus del sarampión se une a la proteína CD46 (proteína cofactor de membrana, MCP) que se encuentra en la mayor parte de los tipos celulares, a la nectina 4 de las células epiteliales y también a la CD150, una molécula de activación de señales en el linfocito (SLAM) que se expresa en los linfocitos T y B activados. ${ }^{13}$ Después de la replicación local del virus en las células epiteliales daña las vías respiratorias. El virus infecta los monocitos y los linfocitos y se disemina por 
el tejido linfático, mediante la viremia asociada con células, se replica en los linfocitos y en las células dendríticas. Así, ocurre una infección en la conjuntiva, las vías urinarias, los pequeños vasos sanguíneos, los sistemas linfático y nervioso central. El periodo de incubación es de 7 a 21 días. ${ }^{14}$ El contagio ocurre 4 días antes y la trasmisibilidad se extiende, incluso, hasta 4 días después de comenzar. La enfermedad puede diagnosticarse tempranamente si un clínico experto detecta numerosas lesiones tipo enantema (lesiones papulares irregulares de tipo granular de color rojizo con el centro blanco-azuláceo o blanco grisáceo) denominadas manchas de
Koplik (Figura 2), que aparecen en la cara interna del carrillo, a nivel del primer o segundo molar inferior, y en el velo del paladar y la mucosa oral (lesiones patognomónicas de la enfermedad) que se observan 2 a 3 días antes de que aparezca el exantema característico y desaparecen al iniciar el exantema dejando una lesión eritematosa. ${ }^{15} \mathrm{El}$ exantema máculo papular es producido por los linfocitos T dirigidos contra las células endoteliales infectadas por el virus del sarampión que revisten el interior de los pequeños vasos sanguíneos. El exantema suele iniciarse en la cara $y$, de forma centrífuga, se disemina al tronco y las extremidades (Figura 2). Otros datos clínicos
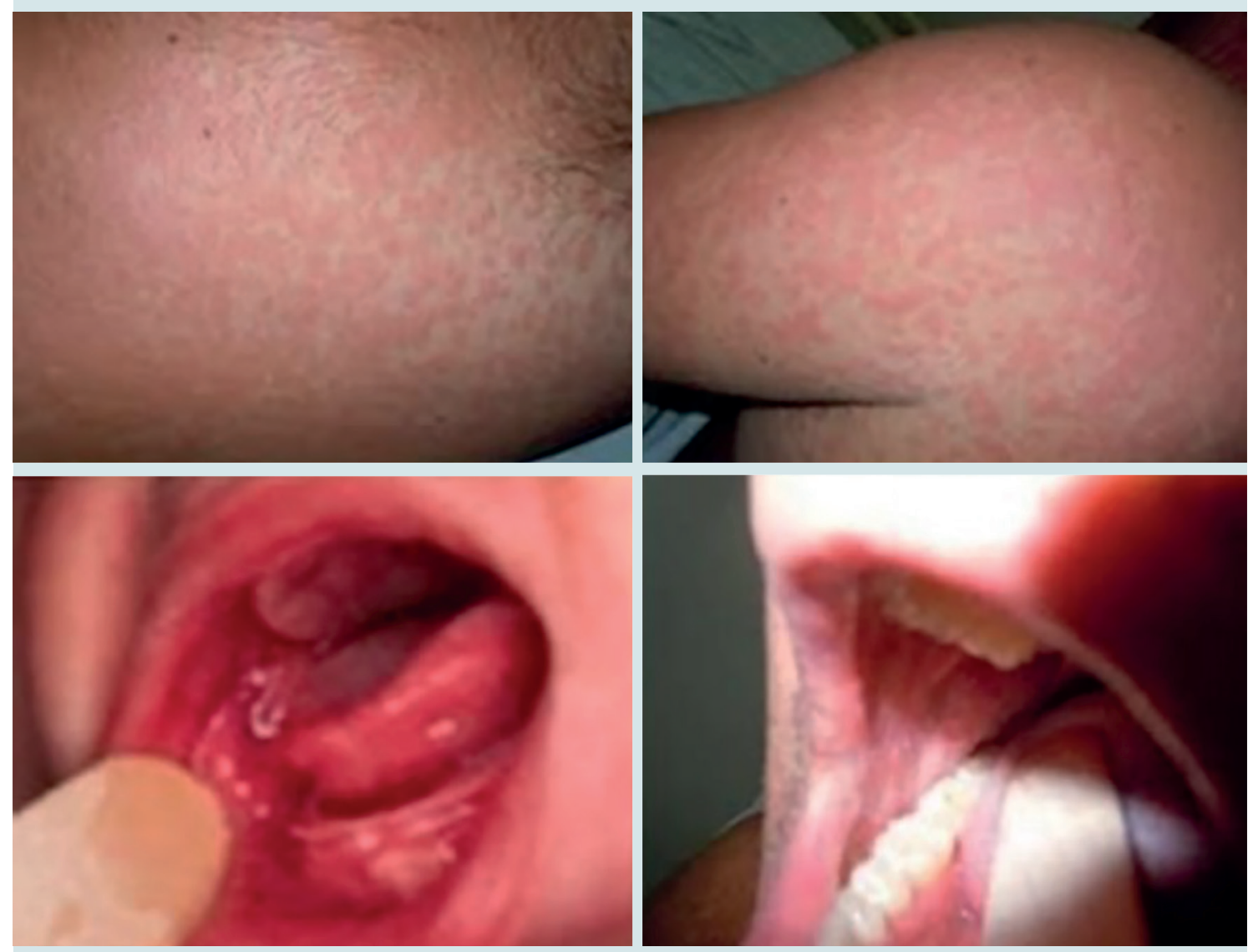

Figura 2. Exantema maculopapular difuso diseminado y manchas de Koplik. Tomado de: Alvarez Baeza C. Manual de vacunación. CENSIA. Documento Técnico. 2017.

https://www.gob.mx/salud\%7Ccensia/documentos/manual-de-vacunacion-edicion-2017. 
son las líneas de Stimson (pequeñas hemorragias en los párpados, manchas de Herman [puntos blancos en la faringe]).

Los síntomas característicos son: fiebre, tos (seca), conjuntivitis y exantema maculopapular; puede haber odinofagia e, incluso, datos de resfriado común, que aparecen aproximadamente entre el décimo o décimo cuarto día posterior a una infección por el virus del sarampión. Características importantes del sarampión son la tos y la conjuntivitis (con lagrimeo o purulenta). De hecho, la escuela francesa consideraba que el sarampión sin tos ni lagrimeo no es sarampión.

El cuadro del sarampión se caracteriza por cuatro etapas secuenciales debidamente definidas con duración de 2 a 3 semanas:

Infección e incubación. Durante los primeros 10 a 14 días después de contraer la infección, el virus del sarampión se incuba. Durante ese lapso no tiene signos ni síntomas.

Fase prodrómica o catarral (signos y síntomas inespecíficos). El sarampión suele iniciarse con fiebre de leve a moderada, y puede alcanzar incluso $40^{\circ} \mathrm{C}$, a menudo acompañada de tos constante, resfrío, conjuntivitis, fotofobia y odinofagia. La fiebre puede durar de 1 a 7 días y la tos de 1 a 2 semanas. La conjuntivitis es intensa en adultos y se asocia con edema palpebral; remite cuando baja la fiebre.

Fase aguda (erupción cutánea). La erupción cutánea de tipo morbiliforme aparece 3 a 4 días posteriores al inicio de la fiebre; consiste en pequeñas manchas rojas e incluso violetas, algunas están levemente elevadas. El puntilleo rojizo y la erupción en grupos le dan a la piel un aspecto rojo moteado. El exantema de tipo maculopapular eritematoso es de 0.1 a $1 \mathrm{~cm}$ de diámetro. Su distribución es cefalocaudal: primero aparece en el rostro en la zona frontal debajo de la línea de implantación del cabello y detrás de los pabellones auriculares (nunca en zonas pilosas).

Durante los siguientes días, el exantema, confluente, se disemina a los brazos, el tronco, los muslos, las piernas y los pies. Al mismo tiempo, la fiebre aumenta rápidamente, suele alcanzar los 40 a $41{ }^{\circ} \mathrm{C}$. El exantema del sarampión disminuye gradualmente; primero desaparece del rostro y, por último, de los muslos y los pies. El exantema palidece y desaparece en el mismo orden en el que apareció, dejando unas manchas de color pardo y descamación fina furfurácea de la epidermis, en promedio en 3 a 7 días. Esta fase dura entre 1 a 2 semanas.

Periodo contagioso y de trasmisibilidad. Una persona con sarampión puede propagar el virus a otras durante, aproximadamente, 8 días; ese periodo comienza 4 días antes del inicio del exantema y finaliza 4 días después del mismo. El virus permanece en el aire y en superficies contaminadas hasta por 2 horas, con un índice de trasmisibilidad o índice básico de reproducción (RO [número promedio de casos nuevos que genera un caso dado a lo largo de un periodo infeccioso.]) de 12 a 18 casos secundarios. ${ }^{16,17,18}$

\section{Complicaciones}

El virus del sarampión puede causar encefalitis a través de tres mecanismos:

1. Infección directa de las neuronas. Se origina un cuadro de encefalomielitis diseminada, derivado de la enfermedad autoinmunitaria desmielinizante (ADEM por sus siglas en inglés).

2. Encefalitis posinfecciosa. Causa un cuadro de encefalitis por cuerpos de inclusión (MIBE por sus siglas en inglés), donde la infección por el virus del sarampión es 
progresiva, con deterioro neurológico y muerte de pacientes con alteraciones de la inmunidad celular ( $\mathrm{VIH}$, trasplantados, etc).

\section{Panencefalitis esclerosante subaguda} (SSPE por sus siglas en inglés). La provoca una variante defectuosa del sarampión que se origina durante la fase aguda del cuadro. En la panencefalitis esclerosante subaguda el virus se replica pobremente, permanece asociado a las células y produce efectos citopatológicos en las neuronas y síntomas muchos años después de la enfermedad aguda. Este evento ocurre en 1 de cada 10,000 a 100,000 casos en niños de 5 a 10 años. Es más frecuente en pacientes que tuvieron sarampión antes de los 2 años y se caracteriza por convulsiones, deterioro cognitivo y de la función motora y muerte..$^{19,20,21}$

\section{Otras complicaciones}

Los niños con deficiencias en los linfocitos T pueden expresar un cuadro de neumonía atípica, que es una neumonía de células gigantes sin exantema, o neumonía de Hecht que se caracteriza por un cuadro de tipo bronquiolítico con dificultad respiratoria, que es un ambiente propicio para la sobreinfección por otros gérmenes, puede ser progresiva y mortal. El sarampión es más grave en pacientes con deficiencia de vitamina A. Ésta es importante para la función adecuada de los linfocitos T.22,23,24

Las complicaciones (30\% de los casos) descritas en niños menores de 5 años incluyen: otitis media aguda (5 a 15\%), neumonía (5 a 10\%), laringitis obstructiva $y$, ocasionalmente, diarrea aguda. Las más frecuentes se registran en los países subdesarrollados o con desnutrición o inmunodepresión. También se describe como complicación grave la encefalitis posinfecciosa en 1 por cada 1000 casos, igual valor de 1 por 1000 casos se reconoce para su letalidad..$^{10,25,26}$

\section{Epidemiología}

En el año 2018 se notificaron en todo el mundo 283,343 casos confirmados de sarampión registrados en 139 países. En diciembre de 2019 se confirmaron 519,490 casos de sarampión distribuidos en más de 180 países afectados; el incremento fue del 83\% con respecto al 2018. El incremento de casos ha sido variable en los diferentes países, al igual que la distribución de los diferentes genotipos conocidos del sarampión. Figura 3

En el último año, los países con mayor cantidad de casos y tasa de incidencia por cada 100,000 habitantes son: Madagascar con 213,287 casos y tasa de incidencia de 799.40, Ucrania con 57,282 casos y tasa de incidencia de 135.89, Filipinas con 47,722 casos y tasa de incidencia de 44.86, Nigeria 28,260 y tasa de incidencia de 14.14 y Brasil con 19,326 y 9.01 de tasa de incidencia; estos países concentran el $70 \%$ de los casos en el mundo. En el Cuadro 1 se muestra una representación de países que permite comparar la cantidad total de casos en los últimos 10 años. Resalta que la distribución de casos no ha sido homogénea ni su aumento en un solo momento; además de los casos que se habían registrado en México, de forma aislada, similar a los que hubo en Chile. El 28\% de los casos que ocurrieron en 2019 se confirmaron por el cuadro clínico, 21\% por laboratorio y $51 \%$ por asociación epidemiológica. La región más afectada fue la africana con 286,936 casos, seguida por la europea con 104,248 y la región del Pacífico Occidental con 61,531 y el resto por las otras tres regiones. ${ }^{26,27}$

\section{Diagnóstico}

En la actualidad, el diagnóstico se fundamenta en tres elementos: el diagnóstico clínico, epidemiológico y de laboratorio. En un paciente con el cuadro clínico deben investigarse los factores de riesgo epidemiológico, contactos, 


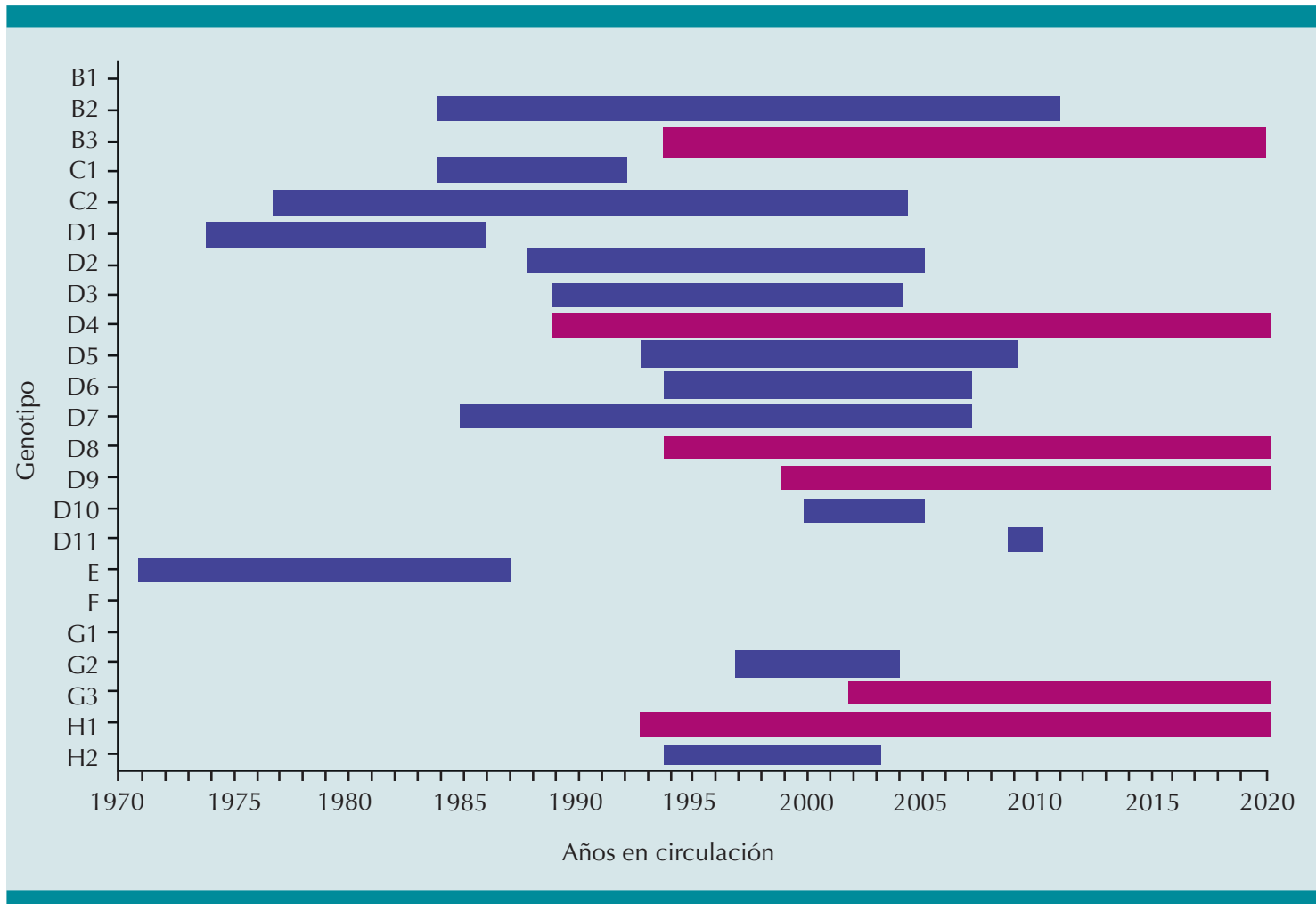

Figura 3. Genotipos de sarampión circulantes en el mundo de 1970 a 2020.

Tomado y modificado de: Coughlin MM, Beck AS, Bankamp B, Rota PA. Perspective on Global Measles Epidemiology and Control and the Role of Novel Vaccination Strategies. Viruses 2017; 9 (11). https://doi.org/10.3390/ v9010011

Cuadro 1. Casos de sarampión de 2010 a 2019 en algunos países representativos

\begin{tabular}{lccccc|c|c|c|c|c|c|c|} 
País & $\mathbf{2 0 1 0}$ & $\mathbf{2 0 1 1}$ & $\mathbf{2 0 1 2}$ & $\mathbf{2 0 1 3}$ & $\mathbf{2 0 1 4}$ & $\mathbf{2 0 1 5}$ & $\mathbf{2 0 1 6}$ & $\mathbf{2 0 1 7}$ & $\mathbf{2 0 1 8}$ & $\mathbf{2 0 1 9}$ & Total \\
\hline Madagascar & 1 & 1 & 3 & 7 & 1 & 6 & 17 & 84 & 23,558 & 213,219 & 23,969 \\
Ucrania & 42 & 1313 & 12744 & 3308 & 2326 & 141 & 90 & 4782 & 53,218 & 57,332 & 147 \\
Estados Unidos & 63 & 220 & 55 & 187 & 667 & 188 & 86 & 120 & 375 & 1,282 & 3,243 \\
México & 0 & 3 & 0 & 2 & 3 & 1 & 0 & 0 & 5 & 20 & 34 \\
Brasil & 68 & 0 & 2 & 192 & 708 & 214 & 0 & 0 & 10,326 & 17,211 & 28,721 \\
Chile & 0 & 6 & 0 & 0 & 0 & 9 & 0 & 0 & 23 & 11 & 49
\end{tabular}

viaje a zonas endémicas. A todo caso sospechoso deben practicársele las pruebas de laboratorio confirmatorias. La definición operacional de la OMS es: exantema maculopapular generalizado, fiebre mayor de $38{ }^{\circ} \mathrm{C}$ acompañada de tos, coriza o conjuntivitis. No debe olvidarse que la presentación clínica puede ser variable en lactantes menores, inmunocomprometidos o pacientes previamente vacunados. El antecedente de vacunación no excluye el diagnóstico. 28,29

El diagnóstico de laboratorio puede confirmarse con: determinación de anticuerpos IgM que son positivos a partir del terecer día del exantema y, 
así permanecen, incluso, hasta 30 a 60 días después. Los títulos de IgG deben ser cuatro veces mayores. La epidemiología molecular de los virus del sarampión es importante en la vigilancia de cepas de sarampión en la circulación mundial, sobre todo durante los brotes. ${ }^{30}$ La genotipificación del virus del sarampión es importante en el seguimiento de las vías de trasmisión durante la investigación de brotes; los reportes de la genotipificación ayudan a confirmar, refutar o detectar las conexiones entre casos. Si dos casos tienen genotipos coincidentes, estos pueden estar vinculados, incluso si tal nexo no es evidente. Hay 8 linajes de virus salvaje $(A, B, C, D, E, F, G, y$ $H)$ y entre ellos se reconocen 23 genotipos (A, B1, B2, B3, C1, C2, D1, D2, D3, D4, D5, D6, D7, D8, D9, D10, E, F, G1, G2, G3, H1 y H2). En la actualidad, los genotipos B1, D1, E, F y G1 se han extinguido y los genotipos circulantes desde 1990 son los A (incluyendo a los de las cepas vacunales que pertenecen a este genotipo), B2, B3, C1, C2, D2, D3, D4, D5, D6, D8, D8, D9, D10, D11, G2, G3, H1, H2. Solo 13 de los 24 genotipos conocidos se han detectado entre 2005 y 2014, y solo 8 desde 2009, lo que sugiere que muchos genotipos ya no circulan. Durante el 2014 se identificaron 6 genotipos a nivel global, B3, D4, D8, D9, G3, H1 (Figura 3). ${ }^{31,32}$

\section{Tratamiento}

El sarampión no tiene un esquema de tratamiento específico. El criterio de hospitalización se basa en las complicaciones. Las recomendaciones se limitan a: control térmico, hidratación y alimentación adecuadas. La OMS recomienda la administración de una dosis oral de vitamina A (200,000 UI o 100,000 UI en lactantes) por día durante dos días, para los niños con sarampión en las zonas donde puede haber deficiencia de vitamina A. Como parte del tratamiento general se recomienda reposo y para aliviar la fiebre y el malestar: paracetamol, ambiente húmedo (no frío), un antihistamínico para contrarrestar la rinorrea hialina, un ambiente con escasa luz que evite la fotofobia y disminuya la conjuntivitis. 10,33

\section{Prevención}

Las vacunas disponibles son de virus vivos atenuados de la cepa Schwarz, cepa EdmonstonZagreb o cepa Enders (derivada de la Edmonston de sarampión), vigentes desde 1965. Estas cepas atenuadas son del genotipo A, tienen mutaciones que la diferencian del virus salvaje y menor tropismo por los linfocitos.

En México, durante los primeros 70 años del siglo XX, el sarampión fue una de las principales causas de morbilidad y mortalidad. En 1960 comenzó la vacunación contra esta causa pero no fue sino hasta 1973 cuando se inició formalmente el Programa Nacional de Inmunizaciones. En ese año se aplicaron 3.6 millones de dosis de esta vacuna. Se inició la aplicación de la vacuna contra el sarampión tipo Schwarz en 1970 y en 1978 se cambió a la cepa Edmonston-Zagreb. Después de 1990 se incorporó al esquema de inmunizaciones en México la revacunación a los 6 años. A partir de 1998 se sustituye la vacuna antisarampión monovalente por la vacuna triple viral que incluye, además, rubéola y parotiditis.

En el año 2000 se inició la aplicación de la vacuna sarampión-rubéola para niños mayores de 10 años y adultos que no hubieran sido vacunados, con esquema incompleto o desconocido. En 2008 se llevó a cabo la campaña nacional de vacunación masiva contra el sarampión y la rubéola en la población de 19 a 29 años para la erradicación de la rubéola y el síndrome de rubéola congénita. ${ }^{10,34,35}$

No se recomienda suministrar la vacuna a personas con inmunodeficiencias, excepto con la infección por VIH en estado asintomático. ${ }^{10} \mathrm{De}$ manera semejante, en la Norma respectiva relacionada con el VIH y SIDA se contraindica la vacuna triple viral en niños sintomáticos o con inmunodeficiencia grave. En el caso de los adultos infectados se contraindican todas las vacunas de virus vivos. 


\section{Reemergencia en México}

En América, el brote inició en 2017 en Venezuela, se extendió a Brasil y Colombia en 2018. Entre el 1 de enero de 2019 y el 24 de enero de 2020 se notificaron 20,430 casos confirmados de sarampión, incluidas 19 defunciones, en 14 países y territorios de la región: Argentina $(n=114)$, Bahamas ( $n=3)$, Brasil $(n=18,073$, incluidas 15 defunciones), Canadá $(n=113)$, Chile $(n=12)$, Colombia ( $n=242$ casos, incluida 1 defunción), Costa Rica ( 10$)$, Cuba $(n=1)$, Curazao $(n=$ $1)$, Estados Unidos $(n=1282)$, México $(n=20)$, Perú $(\mathrm{n}=2)$, Uruguay $(\mathrm{n}=9)$ y Venezuela $(\mathrm{n}=$ 548 , incluidas 3 defunciones). Brasil contribuyó con el $88 \%$ del total de los casos confirmados en las Américas. ${ }^{36,37}$

Para el 2019, los casos en América se concentraron en 10 países, y al 10 de abril del 2020 se habían reportado 1104 casos confirmados. ${ }^{38}$

\section{Cuadro 2}

En México, la última epidemia de sarampión ocurrió en 1989-1990 y se reportaron 89,163 casos; el último caso autóctono en nuestro país se registró en 1995. En el periodo de 2000 a 2019 se identificaron 185 casos importados o asociados con importación. En la última década solo se notificaron 34 casos. Durante el 2019 el total de casos reportados fue de 20; en la Figura 4 se registra la distribución por grupos de edad, las dosis de vacuna recibida o no recibida en los diferentes grupos señalados. ${ }^{39}$

Entre la semana epidemiológica 7 y 14 del 2020, se reportaron 1443 casos probables de sarampión y se confirmaron 124 casos, 991 se descartaron y 328 permanecen en investigación.

El primer caso de sarampión durante el año en curso inició con síntomas el 23 de febrero, con antecedente de vacunación; se trató de una niña de 8 años. Desde entonces al 12 de junio se reportaron 181 casos. Con un pico máximo por inicio de exantema en la semana epidemiológica
Cuadro 2. Casos de sarampión en América y genotipo aislado

\begin{tabular}{|c|c|c|c|}
\hline País & 2019 & 2020 & $\begin{array}{l}\text { Genotipificación del } \\
\text { virus del sarampión }\end{array}$ \\
\hline Argentina & 107 & $54(1)$ & $\begin{array}{c}\text { Genotipo D8, linaje } \\
\text { MVs/Gir Somnath. } \\
\text { IND/42.16 }\end{array}$ \\
\hline Bahamas & 3 & & \\
\hline Brasil & $18,203(3)$ & 909 (4) & $\begin{array}{c}\text { Genotipo D8, linaje } \\
\text { MVs/Gir Somnath. } \\
\text { IND/42.16 }\end{array}$ \\
\hline Canadá & 113 & 1 & \\
\hline Chile & 11 & 2 & \\
\hline Colombia & $244(1)$ & & \\
\hline Costa Rica & 10 & & \\
\hline $\begin{array}{l}\text { Estados } \\
\text { Unidos }\end{array}$ & 1282 & 12 & \\
\hline México & 20 & 124 & $\begin{array}{c}\text { Genotipo D8, linaje } \\
\text { MVs/Gir Somnath. } \\
\text { IND/42.16 }\end{array}$ \\
\hline Venezuela & $538(3)$ & & \\
\hline Uruguay & & 2 & \\
\hline
\end{tabular}

11, en la que se registraron 45 casos confirmados, el 9 de marzo fue el día con mayor registro de casos por inicio de exantema $(n=13){ }^{39}$

La mayor cantidad de casos se concentra en la Ciudad de México con el 77.7\% ( $\mathrm{n}=140)$, seguida por el Estado de México 21\% ( $\mathrm{n}=38)$ y solo 2 casos en Campeche (1.2\%). La alcaldía que concentra el $43 \%$ de los casos en México es la Gustavo A. Madero ( $\mathrm{n}=75)$, donde hubo varios casos en la población concentrada en un reclusorio, y en el Estado de México el municipio que predomina es Ecatepec 7. 1\% $(n=11)$. El mayor número de casos fue en niños mayores de 11 años, correspondiendo el $57 \%$ a hombres ( $\mathrm{n}$ $=104)$ y $43 \%$ mujeres $(n=77)$. En el grupo de edad de 20 a 39 años ocurrieron 67 casos (38\%) hasta el 12 de junio del 2020. Con una media de edad de 17 años 6 meses, en menores de 1 año se han registrado 21 casos (11\%).

Los grupos de edad más afectados son de 25 a 39 años $(26 \%, \mathrm{n}=47)$ y de 1 a 4 años de edad $(22 \%, \mathrm{n}=39)$. Figura 5 
Respecto al antecedente de vacunación el 81\% de los casos confirmados (146) no tenía registro de la misma en la cartilla y solo el $19 \%(n=35)$ tenía el antecedente de haberse aplicado por lo menos una dosis.

Los casos confirmados con antecedente de vacunación se registraron con mayor frecuencia en los grupos de edad de 2 a 4 años, de 5 a 9 años y de 20 a 39 años. ${ }^{40,41}$

El diagnóstico fue clínico en $2.7 \%$ de los casos $(\mathrm{n}=5)$, porque no se tomó muestra o la serología fue indeterminada; $3.3 \%(n=6)$ mediante IgM positiva y el resto fue mediante reacción en cadena de polimerasa $(93.9 \%, n=170)$. De las cepas
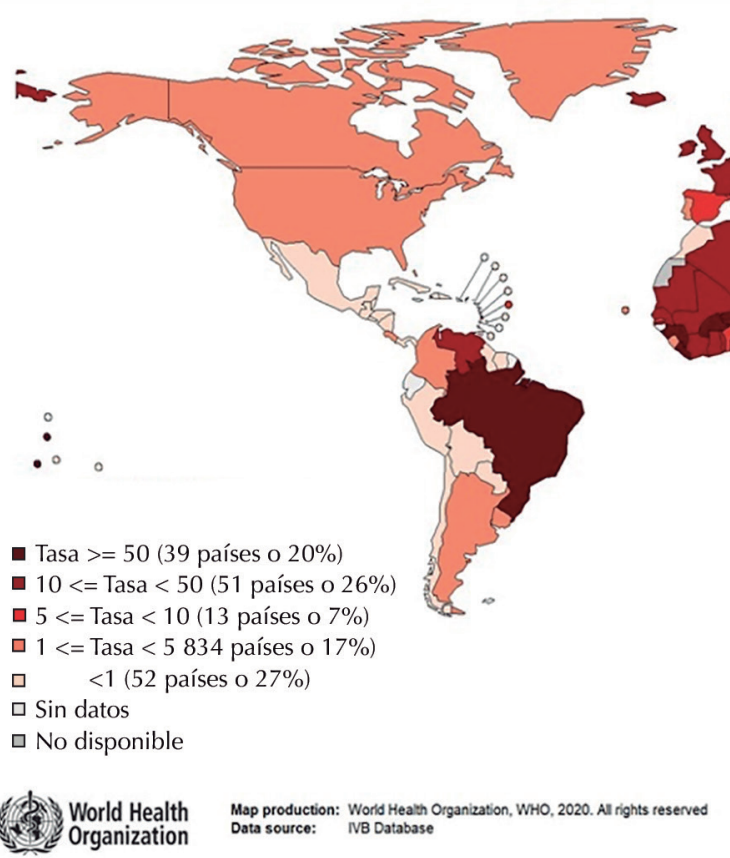

World Health Organization

Map production: Wordd Heath Organization, WHO, 2020. Al rights reserved Data source: IVB Database

Oisclaimer:

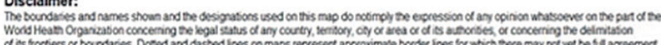

\begin{tabular}{l|c|c|}
\hline Top 10** & & \\
\hline País & Casos & Tasa \\
\hline Madagascar & 95387 & 3821.64 \\
\hline Ucrania & 32160 & 723.69 \\
\hline Filipinas & 29358 & 284.15 \\
\hline Nigeria & 22286 & 119.82 \\
\hline República Democrática del Congo & 21420 & 271.05 \\
\hline Brasil & 18632 & 89.73 \\
\hline Kazajistan & 12107 & 673.07 \\
\hline India**** & 8743 & 6.6 \\
\hline Bangladesh & 6214 & 38.13 \\
\hline Yemen & 4680 & 169.66 \\
\hline
\end{tabular}

Figura 4. Distribución mundial del sarampión según la OMS. https://www.who.int/immunization/monitoring_surveillance/burden/vpd/surveillance_type/active/measles_v**monthlydata/en/

Basado en datos recibidos al 04-2020, cubriendo el período entre 03-19 y 02-20; Incidencia: cantidad de casos**/1,000,000 población; población *mundial de la revisión 2019** 


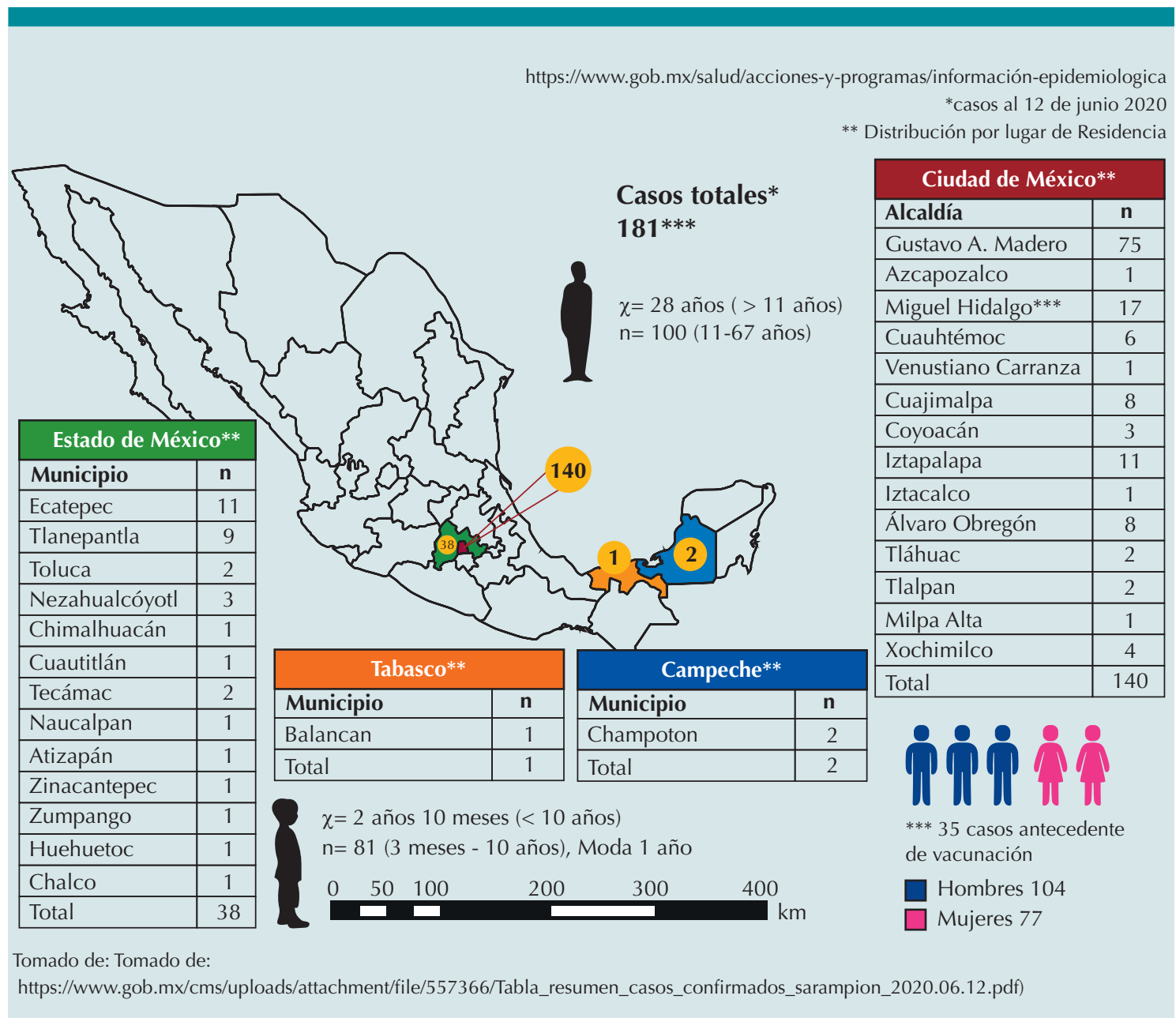

Figura 5. Distribución de casos en México, por grupos de edad, alcaldía o municipio (casos reportados al 12 de junio de 2020).

identificadas todas pertenecen al genotipo D8 ( $\mathrm{n}$ $=25,13.8 \%)$ y Mvs/GirSomnath.IND/42.16 (n $=24,13.2 \%) .{ }^{42,43}$

\section{Recomendaciones}

Debido al resurgimiento de brotes en diferentes países, entre ellos México, donde se había limitado la cantidad de casos, se sospechaba de la reemergencia del sarampión. En 2017, México reportó a la OMS una cobertura de
$79 \%$ para la primera dosis de la vacuna triple viral y $62 \%$ para la segunda dosis, por lo que se clasificó como un país de riesgo para contraer la enfermedad. ${ }^{15}$ De acuerdo con los datos registrados en el Banco Mundial, la cobertura de la primera dosis no ha descendido a menos de $89 \%$ entre 2000 y 2017 , pero el registro de casos en el grupo de 1 a 4 años de edad señala que, seguramente, la cobertura de vacunación con la primera dosis, incluso en las zonas urbanas, es mucho menor. 
En México, a partir de la identificación del primer caso en 2020, el sarampión se ha incrementado de manera exponencial. Ha coincidido con la implementación de medidas de aislamiento al ocurrir con la pandemia de COVID-19 a partir de marzo del 2021; sin embargo, no se ha contenido el surgimiento de los casos, para evitar el restablecimiento de la trasmisión endémica. Debe fortalecerse la activación de los grupos de respuesta rápida capacitados para este fin e implementar protocolos nacionales de respuesta rápida para hacer frente a los casos importados. En este momento, la situación es compleja debido a la restricción de actividades para la contención de la pandemia de COVID-19. Entre las recomendaciones nacionales se consideraba que los individuos mayores de 50 años no requerían la vacuna porque debido a las epidemias previas era muy probable que ya tuvieran inmunidad; sin embargo, el caso del paciente de 68 años hace razonar esta indicación.

Es importante no solo ampliar la cobertura de vacunación a niños de 1 año sino completar los esquemas de vacunación en todo el grupo de menores de 6 años. Debe fomentarse la vacunación en adultos jóvenes y favorecer que el adulto tenga un conocimiento confiable con respecto al esquema de su vacunación que le permita actualizarlo continuamente.

\section{CONCLUSIONES}

A pesar de las actuales condiciones generadas por la pandemia del COVID-19 debe continuarse con la vacunación universal para niños y adolescentes no solo contra el sarampión sino del resto de las enfermedades susceptibles de prevención mediante la vacunación. El sarampión es una enfermedad de alta trasmisibilidad y mortalidad elevada en niños menores de 5 años. El registro de mujeres en edad fértil y con sarampión hace necesario mejorar la cobertura de vacunación a este grupo. El brote actual de sarampión es un desafío de salud pública inmerso en otra situación emergente: la del COVID-19 y, como dice el dicho: "No hay mal que por bien no venga"; habrá que agradecerle a esta pandemia haber llegado poco antes que el sarampión y haber conseguido que un porcentaje alto de la población no saliera de casa con lo que se evitó de manera muy importante el contagio sin repercusión significativa en la morbilidad y mortalidad.

\section{REFERENCIAS}

1. De Vries RD, Duprex WP, de Swart RL. Morbillivirus infections: An introduction. Viruses 2015; 7: 699-706. https:// doi.org/10.3390/v7020699.

2. Aviso Epidemiológico CONAVE /01/2019/SARAMPION 15 de FEBRERO del 2019. https://www.gob.mx/cms/uploads/ attachment/file/438120/AE-Sarampion-15022019.pdf

3. Mina M.J., Metcalf C.J., de Swart R.L., Osterhaus A.D., Grenfell B.T. Long-term measles-induced immunomodulation increases overall childhood infectious disease mortality. Science 2015; 348: 694-99. doi: 10.1126/science.aaa3662.

4. Coria-Lorenzo jj, Calva-Rodriguez RG, Unda-Gómez JJ, Martínez-Nuñez JG, Garcia Carrillo LE, Neme-Díaz GA, Soto Ramos $M$, et al. Consenso sobre la Infección por COVID-19 (SARSCoV-2). Rev Enferm Infecc Pediatr. 2020;32(132)1656-91.

5. Delpiano L, Astroza L, Toro J. Sarampión: la enfermedad, epidemiología, historia y los programas de vacunación en Chile. Revista Chilena de Infectología 2015; 32 (4): 417-29.

6. Huygelen CV. The Immunization of Cattle against Rinderpest in Eighteenth-Century Europe. Medical History, 1997; 41: 182-96.

7. Furuse $Y$, Suzuki A, Oshitani H. Origin of measles virus: Divergence from rinderpest virus between the 11th and 12th centuries. Virology Journal 2010; 7 (1): 52. https:// doi.org/10.1186/1743-422X-7-52.

8. Enders JF, Katz SL, Milovanovic MV, Holloway A. Studies on an attenuated measles-virus vaccine. I. Development and preparations of the vaccine: technics for assay of effects of vaccination. N Engl J Med 1960; 263: 153-59.

9. https://www.who.int/immunization/documents/Measles_Spanish.pdf Vacunas contra el Sarampión. Consultado el 06-Mayo del 2020.

10. Field JC, Coria JJ, Garcia KCR. Sarampión. En: Coria JJ, Ortíz EG Eds; Modelos diagnósticos y algoritmos mentales en procesos infecciosos más comunes en Pediatría. Indicaciones, manejo e interpretación de muestras de laboratorio. 2021. En Prensa.

11. Feigin and Cherry`s Textbook of Pediatric Infectious Diseases. 7a ed. Elsevier, 2014: Measles virus, Cherry J, Capítulo 179: 2373-95. 
12. Delpiano L, Astroza L, Toro J. Sarampión: la enfermedad, epidemiología, historia y los programas de vacunación en Chile. Rev Chilena Infectol 2015; 32 (4): 417-29. http:// dx.doi.org/10.4067/S0716-10182015000500008.

13. Tahara M, Ohno S, Sakai K, Ito $Y$, Fukuhara H, Komase $K$ et al. The receptor-binding site of the measles virus hemagglutinin protein itself constitutes a conserved neutralizing epitope. J Virol. 2013; 87 (6): 3583-3586

14. PatrickR. Murray, PhD., Ken S. Rosenthal, PhD., Michael A. Pfaller, MD. 2017. "MICROBIOLOGÍA MÉDICA"., 8a Edición., Ed. Elsevier.

15. Tierney Jr. LM, Wang KC. Koplik's spots. N Engl J Med 2006; 354(7): 740.

16. Sarampion Clinical Guidelines https://medicalguidelines. msf.org/viewport/CG/latest/sarampion-23443287.html

17. Sarampión- Enfermedades víricas https://empendium. com/manualmibe/chapter/B34.II.18.1.3.

18. Sarampión-Pediatría- Manual MSD versión para profesionales

19. https://www.msdmanuals.com/es/professional/ pediatr\%C3\%ADa/infecciones-virales-diversas-en-lactantes-y-ni\%C3\%B1os/sarampi\%C3\%B3n

20. Nambulli S, Sharp CR, Acciardo AS, Drexler JF, Duprex WP. Mapping the evolutionary trajectories of morbilliviruses: what, where and whither. Curr Opin Virol 2016; 16: 95-105.

21. Moss WJ, Griffin DE. Sarampión. Lancet 2012; 379: 153-64.

22. Ludlow M, McQuaid S, Milner D, de Swart RL, Duprex WP. Pathological consequences of systemic measles virus infection. J Pathol 2015; 235: 253-65.

23. Herrera-Benavente, Ismael Francisco, Mascareñas-de los Santos Abiel Homero, Rodriguez-Barragan Enrique, et. Al. Estado actual del sarampión Comportamiento en Latinoamérica. Rev Lat Infect Ped; Vol 31 (4) 2019:140-148.

24. Gershon AA. Measles virus. In: Mandell, Douglas and Bennett's. Principles and practice of infectious diseases. 8th ed. Canada: Elsevier-Saunders; 2015. pp. 1967-1973

25. Plattet $P$, Alves L, Herren M, Aguilar HC. Measles virus fusion protein: structure, function and inhibition. Viruses. 2016; 8: 112

26. Actualización Epidemiológica de Sarampión del 28 de febrero de 2020, Washington, D.C. OPS/OMS. 2017. Disponible en https://bit.ly/2jErtHU

27. Vargas- Almanza-Ivan de Jesus, Aragón-Nogales,Ranferi, Miranda-Novales Maria Guadalupe. Situación actual del sarampión en México y en el mundoRev Mex Pediatr. 2019; 86(4); 133-137.

28. WHO | Measles and Rubella Surveillance Data - World Health Organization

29. https://www.who.int/immunization/monitoring_surveillance/burden/vpd/surveillance_type/active/measles_monthlydata/en/
30. Orenstein WA1, Cairns L2, Hinman A3, Nkowane B4, Olivé JM5, Reingold AL Measles and Rubella Global Strategic Plan 2012-2020 midterm review report: Background and summary Vaccine. 2018 :11;36 Suppl 1:A1-A34.

31. Moss WJ1 Measles. Lancet. 2017 Dec 2;390(10111):24902502

32. Misin A1, Antonello RM2, Di Bella S1, Campisciano G3 Measles: An Overview of a Re-Emerging Disease in Children and Immunocompromised Patients Microorganisms. 2020; 8(2): 276

33. Husada Dominicus, DwiyantiKusdwijono Leny Puspitasari, An evaluation of the clinical features of measles virus infection for diagnosis in children within a limited resources settingBMC Pediatr. 2020; 20: 5.

34. Rota PA, Featherstone DA, Bellini WJ Molecular epidemiology of measles virus.Curr Top Microbiol Immunol. 2009; 330():129-50.

35. Coughlin, Melissa M. Beck Andrew S, Bankamp, Bettina Perspective on Global Measles Epidemiology and Control and the Role of Novel Vaccination StrategiesViruses. 2017; 9(1): 11

36. Huiming $\mathrm{Y}$, Chaomin W, Meng M. Vitamina A para el tratamiento del sarampión en niños (Revisión Cochrane traducida). En: La Biblioteca Cochrane Plus, número 3, 2008. Oxford, Update Software Ltd. Disponible en: 28. http:// www.update-software.com. (Traducida de The Cochrane Library, Issue . Chichester, UK: John Wiley \& Sons, Ltd.)

37. Santos JI. El Programa Nacional de Vacunación: orgullo de México. Rev Fac Med UNAM. 2002; 45(3): 142-153.

38. Aviso Epidemiológico Sarampión, Comité Nacional para la Vigilancia Epidemiológica. CONAVE/04/2018/SARAMPIÓN, Disponible en: https://www.gob.mx/cms/uploads/attachment/file/341222/AE_Sarampion03072018.pdf

39. Actualización Epidemiológica de Sarampión 6 de febrero de 2018 Organización Panamericana de la Salud • www. paho.org • (c) OPS/OMS, 2020

40. Aviso Epidemiológico Sarampión, Comité Nacional para la Vigilancia Epidemiológica. CONAVE/01/2019/SARAMPION 15 de febrero del 2019. Disponible en: https:// www.gob.mx/cms/uploads/attachment/file/438120/AESarampion-15022019.pdf

41. Actualización Epidemiológica de Sarampión 28 de febrero de 2020 Organización Panamericana de la Salud • www. paho.org • (c) OPS/OMS, 2020

42. Aviso Epidemiológico Sarampión, Comité Nacional para la Vigilancia Epidemiológica. CONAVE /07/ 2020/SARAMPIÓN, Disponible en: https://www.gob.mx/cms/uploads/ attachment/file/541291/Aviso Epidemiol gico_DVEET Sarampi_n_13mar2020_vFinal.pdf

43. Boletín Informativo No. 8 sobre Situación actual del Brote por Sarampión, México 2020. Subsecretaría de Prevención y Promoción de la Salud Dirección General de Epidemiología.29-Mayo-2020 
García-Carrillo LE, et al. Sarampión en México: 2020

44. Tabla_resumen_casos_confirmados_sarampión_2020.06.12 https://www.gob.mx/salud/documentos/casos-confirmados-por-sarampion-2020

45. Boletín Informativo No. 9 sobre Situación actual del Brote por Sarampión, México. 5 de junio de 2020. 42. http://www.

ssm.gob.mx/portal/sarampion/descargables/boletines/Boletin\%209\%20SARAMPION_05\%2006\%202020\%20(177).pdf

46. Tabla_resumen_casos_confirmados_sarampión_2020.06.12 https://www.gob.mx/salud/documentos/casos-confirmadospor-sarampion-2020 